Journal of Clinical Investigation

Vol. 41, No. 2, 1962

\title{
METABOLIC ADAPTATIONS TO A "STUFF AND STARVE" FEED- ING PROGRAM. II. OBESITY AND THE PERSISTENCE OF ADAPTIVE CHANGES IN ADIPOSE TISSUE AND LIVER OCCURRING IN RATS LIMITED TO A SHORT DAILY FEEDING PERIOD*
}

\author{
By GUY HOLLIFIELD AND WILLIAM PARSON
}

(From the Department of Internal Medicine, University of Virginia School of Medicine, Charlottesvile, $V a$.)

(Submitted for publication June 2, 1961 ; accepted September 28, 1961)

Many obese people who want to lose weight seem unable to follow diets which will allow them to achieve and maintain ideal weight (1-3). This failure to follow diets has been ascribed to a lack of interest or to psychological factors, since no clear-cut abnormality in so-called simple or exogenous obesity other than excessive food intake has been delineated (4).

However, many obese patients consume most of their food within a relatively short period each day (5), and an interest in this unusual eating pattern prompted a study of rats allowed access to more food than they were able to consume for periods of up to 7 days. These studies (6) showed that adipose tissue from these animals developed a very remarkable ability to incorporate large amounts of acetate-1- $\mathrm{C}^{14}$ into lipids in vitro after 5 days on this program. This increase in acetate incorporation into lipids is accompanied by striking increases in glucose-6phosphate dehydrogenase and 6-phosphogluconate dehydrogenase activity in adipose tissue homogenates. Liver glycogen in animals fasted for 24 hours after being allowed food for only 2 hours per day, for 4 or 5 days, was much higher than it was in rats fed ad libitum after a similar fast.

These observations have prompted the present investigations in which we have studied the effects, over a longer period of time, of this type of feeding program on body weight of rats, and have attempted to learn how long these adaptive changes persist when the animals are again allowed food ad libitum.

\footnotetext{
* Presented in part at the meeting of the Southern Society for Clinical Research, New Orleans, La., January, 1961. These studies were supported in part by Grant no. A-893, United States Public Health Service.
}

\section{MATERIALS AND METHODS}

Several experiments as outlined below were done. Male rats of the Sprague-Dawley strain were used in all studies. Purina laboratory chow pellets were used as feed. Acetate-1- $\mathrm{C}^{14}$ incorporation into lipids by adipose tissue (epididymal fat pads) in vitro was measured by the method of Baruch and Chaikoff (7). Two $\mu$ moles of acetate-1-C $\mathrm{C}^{\mathbf{1 4}}$ containing $2 \mu \mathrm{c}$ of radioactivity was added to each flask containing approximately $400 \mathrm{mg}$ of tissue and incubated for 3 hours at $37^{\circ} \mathrm{C}$. The free fatty acid (FFA) content of adipose tissue was determined using a modification of Dole's method (8). Measurements of liver glycogen were made by the modified method of Pflueger (9).

Experiment 1. Thirteen young male rats of the Sprague-Dawley strain were studied. All weighed between 122 and $126 \mathrm{~g}$ at the time the study was begun. The animals were kept in individual cages in a room at $70^{\circ} \mathrm{F}$ with 12 hours of light each day. Five animals were allowed food ad libitum and 8 were allowed access to food for only 2 hours each day. These 8 animals were allowed access to more food than they consumed from 8:00 to 10:00 a.m. each day. Both groups were allowed water ad libitum. Food intake for both groups was measured daily. Individual body weights were determined every other day for the first 2 weeks and twice weekly thereafter.

Experiment 2. Six rats weighing 200 to $220 \mathrm{~g}$ were allowed food from 8:00 to 10:00 a.m. for 7 days and then allowed food ad libitum for 7 days. On the eighth day they were fasted for 24 hours and again allowed food from 8:00 to 10:00 a.m. Immediately after the feeding period they were killed by a blow on the head. Samples of epididymal fat were taken for measurements of acetate-1-C:4 incorporation into lipids and FFA content. Slices of liver for glycogen were put into 30 per cent potassium hydroxide as rapidly as possible after each animal was killed.

Food intake during the 2 -hour feeding period was determined. When the animals were again permitted food ad libitum, food intake was determined for the periods $8: 00$ a.m. to $12: 00$ noon, $12: 00$ noon to $2: 00$ p.m. and 4:00 p.m. to 8:00 a.m.

Experiment 3. Six rats weighing 200 to $220 \mathrm{~g}$ were allowed access to food from 8:00 to 10:00 a.m. for 7 


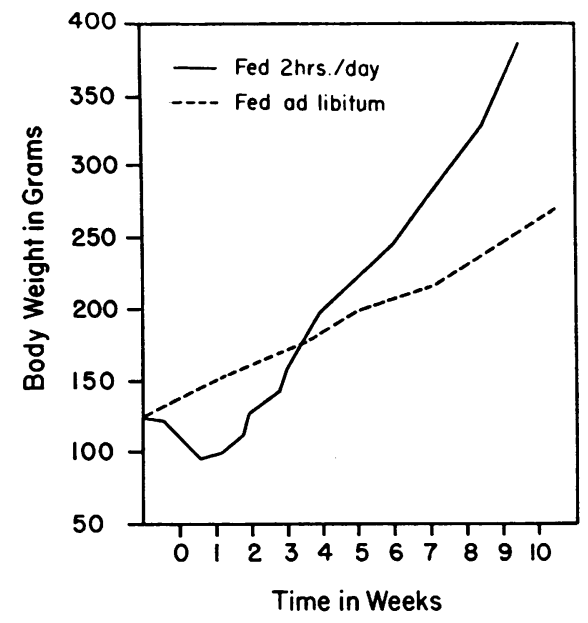

Fig. 1. Average body Weights of rats allowed FOOD FOR ONLY 2 HOURS PER DAY AND RATS ALLOWED FOOD AD LIBITUM.

days and then allowed food ad libitum for 20 to 28 days. They were then fasted for 22 hours and again allowed food from 8:00 to 10:00 a.m. They were killed at the end of the feeding period and studied as outlined in Experiment 2 .

Experiment 4. Six rats weighing 190 to $210 \mathrm{~g}$ were allowed access to food from 8:00 to 10:00 a.m. for 7 days and then fasted for 3 days (less 2 hours). At the end of the fast they were allowed food for 2 hours (8:00 to 10:00 a.m.), killed, and studied as in Experiment 2 .

\section{RESULTS}

The changes in body weight for the animals in Experiment 1 are given in Figure 1 . The rats fed ad libitum averaged $287 \pm 32 \mathrm{~g}$ after 10 weeks, while those allowed food only 2 hours per day averaged $383 \pm 13 \mathrm{~g}$. As for food intake, the daily average intake of the animals allowed food only 2 hours per day was lower than those eating ad libitum for the first 3 or 4 days and then it equaled theirs for several days, rising then to exceed the daily intake of the ad libitum controls by approximately 5 to 15 per cent through the remainder of the study period.

The data on acetate-1- $\mathrm{C}^{14}$ incorporation into adipose tissue in vitro, FFA content of adipose tissue, and liver glycogen for the animals in Experiments 2 and 4 are given in Figure 2 . These data are compared with similar data from previous studies (6) on 6 rats fed ad libitum, fasted for 22 hours, and fed for 2 hours (controls 1 day) and from 6 rats allowed food for 2 hours per day for 5 days, both groups having been studied immediately after the 2-hour feeding period on Days 1 and 5. In Figure 2 it is apparent that animals fed for 2 hours per day for 7 days, allowed to eat ad libitum for 7 days, fasted 22 hours, and then allowed food for 2 hours, still show high rates of acetate-1- $\mathrm{C}^{14}$ incorporation into lipids in adipose tissue in vitro, low FFA levels in adipose tissue, and a moderate increase in liver glycogen, when compared with animals fed ad libitum which had been fasted for 22 hours and allowed to eat for 2 hours. The animals in Experiment 2 were able to adjust to the 2-hour feeding period very quickly and by the fourth day all were eating as much as they had been eating on ad libitum feeding before the beginning of the experiment. During the subsequent ad libitum feeding period these animals consumed over 60 per cent of their daily

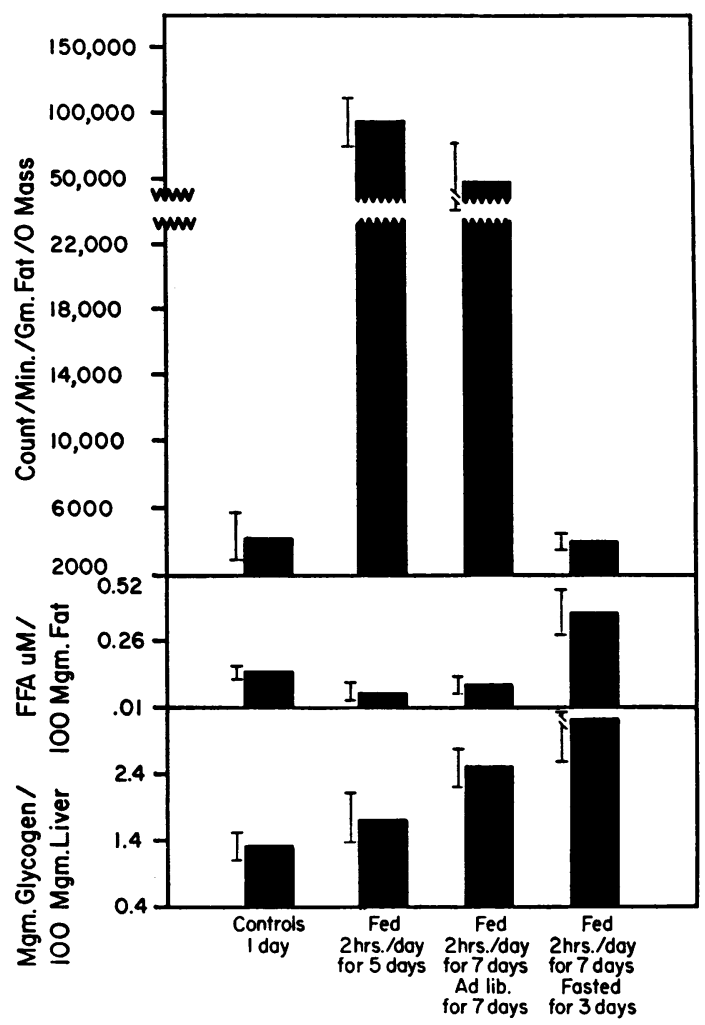

Fig. 2. InCORPORATION OF ACETATE-1-C $C^{14}$ INTO LIPIDS BY ADIPOSE TISSUE in vitro, FFA CONTENT OF ADIPOSE TISSUE, AND LIVER GLYCOGEN, IN FOUR GROUPS OF RATS STUdied AT THE ENd OF A 2-HOUR FEeding PERIOD. The controls previously fed ad libitum were fasted for 22 hours and allowed food for 2 hours. The second group was studied at the end of the 2 -hour feeding after 5 days of being allowed food for only 2 hours per day. The third group was studied after being prepared as outlined in Experiment 2, and the last group as outlined in Experiment 4. Bars represent 1 standard deviation from the mean. 
food intake in the period from 8:00 a.m. to $12: 00$ noon.

Data on the animals in Experiment 3 are not given. Acetate-1- $\mathrm{C}^{14}$ incorporation into lipids by adipose tissue, FFA content of adipose tissue, and liver glycogen in these animals were not different from the controls shown in Figure 2.

In the animals in Experiment 4 the 3-day fast after 7 days of feeding for 2 hours per day reduced the amount of acetate-1- $\mathrm{C}^{14}$ incorporation into lipids by adipose tissue occurring after the 2-hour feeding period. This low acetate incorporation was associated with higher levels of FFA in adipose tissue and more liver glycogen than were present in the controls.

\section{DISCUSSION}

These studies indicate that rats allowed food for only 2 hours per day gain more weight than animals eating ad libitum. This increase in body weight on gross inspection of the animals appears to be due to increased fat deposition and is associated with an increased food intake. These studies extend earlier observations $(10,11)$ that rats can be trained to consume enough food in 1 hour per day to permit growth and that respiratory quotient measurements on these intact animals and on surviving liver slices indicate increased lipogenesis. Tepperman and Tepperman (12) have reported that liver slices from animals fed for 1 hour per day show increased incorporation of acetate-1- $\mathrm{C}^{14}$ and glucose- $\mathrm{U}-\mathrm{C}^{14}$, which is associated with increased hexose monophosphate shunt enzyme activity in this tissue. In other studies (6) we have demonstrated a greater and more rapid acetate-1- $\mathrm{C}^{14}$ incorporation into lipids in surviving adipose tissue slices, which was associated with increased glucose-6-phosphate dehydrogenase and 6-phosphogluconate dehydrogenase activity in adipose tissue homogenates. These changes occur very rapidly when rats are limited to a 2-hour feeding period each day and help delineate the mechanism by which rats adapt themselves to handling a very large food intake in a short period of time.

The presence of hypothalamic centers which regulate feeding activity in rats is well established $(13,14)$. Destruction of the ventromedial nuclei of the hypothalamus produces hyperphagia in a variety of species which is apparently due to a loss of the so-called "satiety response" (15). Since rats normally consume their food in small amounts over a period of 24 hours, these "satiety centers" apparently exercise fairly fine control over feeding in rats allowed food ad libitum. Thus the adaptation of rats to a 2 -hour feeding period may involve some decreased "sensitivity" of these hypothalamic centers to permit ingestion of large amounts of food in a short time. The present observation on body weight of rats limited in this way suggests that this control is "damped" to a degree that obesity results.

The observations on rats allowed food ad libitum after 7 days of 2 -hour feeding periods show that the metabolic alterations in adipose tissue and liver persist for some time after the 2-hour per day feeding program is discontinued. These changes are probably related to the fact that the eating pattern in these rats remains altered during the ad libitum feeding period.

However, the explanation for the persistence of the abnormal feeding pattern is not clear. It may be that the metabolic alterations in adipose tissue and liver tend to perpetuate this type of feeding pattern, or that the "damped" hypothalamic feeding centers do not recover to the point of exercising normal control for some time, or both.

There is some evidence (15) to suggest that fasting will "sensitize" the satiety centers, permitting small amounts of food to produce a "satiety response" (16), as measured by changes in spontaneous running activity. These observations prompted Experiment 4 in which animals were fasted for 3 days (less 2 hours) after being allowed food for only 2 hours per day for 7 days. The incorporation of acetate-1- $\mathrm{C}^{14}$ into lipids by adipose tissue after a 2-hour feeding period in these animals was low and FFA levels in adipose tissue were high, suggesting that the metabolic alteration in adipose tissue had reverted to that seen in animals fed ad libitum.

However, liver glycogen in these animals was higher than in animals fasted for 22 hours and fed for 2 hours after being fed ad libitum. This observation suggests that the observed metabolic alterations were not entirely reversed since animals fed for 2 hours per day have high levels of liver glycogen, even after fasting.

The one feeding period a day may not be crucial to the development of the changes observed in these studies. Cohn and Joseph (17) have 
shown that rats tube-fed twice daily have increased body fat when compared with pair-fed animals with similar body weights eating ad libitum. This increased body fat is associated with increased hexose monophosphate shunt enzyme activity in liver and adipose tissue homogenates. It is possible that several widely spaced "meals" may result in the metabolic adaptations described here.

Whatever the explanation involved in the observed obesity occurring in rats allowed food for only 2 hours per day and the persistence of the changes in adipose tissue and liver glycogen described, these studies permit some interesting speculation in regard to human obesity. It seems likely that humans who consume most of their food in a short period each day would adjust to this pattern in a fashion similar to the one described here. Once adapted to this eating pattern it is possible that the metabolic adaptation of adipose tissue and liver, or the hypothalamic feeding centers, or both, would tend to perpetuate it. These adaptations would make it difficult for obese patients to limit themselves to small spaced feeding generally used in weight reduction diets.

\section{SUMMARY}

1. After 10 weeks rats allowed access to food for only 2 hours per day were more than 30 per cent heavier than animals allowed food ad libitum.

2. Rats allowed access to food for only 2 hours per day ate more than controls fed ad libitum, within a few days after this feeding program was initiated.

3. Acetate-1- $\mathrm{C}^{\mathbf{1 4}}$ incorporation into lipids by adipose tissue in vitro and liver glycogen remained high in rats allowed food ad libitum for 7 days after 7 days on a 2 -hour per day feeding program. These changes were no longer present after similarly treated rats were allowed food ad libitum for 20 to 28 days.

4. In rats allowed access to food for only 2 hours per day for 7 days, a 3-day fast reduced the rate of acetate-1- $\mathrm{C}^{14}$ incorporation into lipids by adipose tissue in vitro after a 2 -hour feeding period to that of controls fed ad libitum.

5. The implications of these findings in human obesity and the difficulties involved in following weight reduction diets have been discussed.

\section{REFERENCES}

1. Fellows, H. H. Studies of relatively normal obese individuals during and after dietary restrictions. Amer. J. med. Sci. 1931, 181, 301.

2. Daughaday, W. H. Obesity in Textbook of Endocrinology, 2nd ed., R. H. Williams, Ed. Philadelphia, W. B. Saunders, 1955, p. 663.

3. Bouser, L. J., Trulson, M. F., Bowling, R. C., and Stare, F. J. Methods of reducing: Group therapy versus individual clinic interview. $\mathrm{J}$. Amer. diet. Ass. 1953, 29, 1193.

4. Parson, W., and Crispell, K. R. Obesity. DM (Chicago) 1956, Feb.

5. Stunkard, A. J., Grace, W. J., and Wolff, H. G. The night-eating syndrome: Pattern of food intake among certain obese patients. Amer. J. Med. 1955, 19, 78.

6. Hollifield, G., and Parson, W. Metabolic adaptations to a "stuff and starve" feeding program. I. Studies of adipose tissue and liver glycogen in rats limited to a short daily feeding period. J. clin. Invest. 1962, 41, 245.

7. Baruch, H., and Chaikoff, I. L. A simplified method for determination of lipide- $\mathrm{C}^{\mathbf{1 4}}$ in liver. Proc. Soc. exp. Biol. (N. Y.) 1954, 86, 97.

8. Dole, V. P. A relationship between non-esterified fatty acids in plasma and the metabolism of glucose. J. clin. Invest. 1956, 35, 150.

9. Good, C. A., Kramer, H., and Somogyi, M. The determination of glycogen. J. biol. Chem. 1933, $100,485$.

10. Tepperman, J., Brobeck, J. R., and Long, C. N. H. The effects of hypothalamic hyperphagia and of alterations in feeding habits on the metabolism of the albino rat. Yale J. Biol. Med. 1943, 15, 855.

11. Dickerson, V. C., Brobeck, J. R., and Long, C. N. H. The role of liver in the synthesis of fatty acids from carbohydrate. Yale J. Biol. Med. 1943, 15, 875.

12. Tepperman, J., and Tepperman, H. M. Effects of antecedent food intake pattern on hepatic lipogenesis. Amer. J. Physiol. 1958, 193, 55.

13. Hetherington, A. The relation of various hypothalamic lesions to adiposity and other phenomena in the rat (abstract). Amer. J. Physiol. 1941, 133, P326.

14. Brobeck, J. R., Tepperman, J., and Long, C. N. H. Experimental hypothalamic hyperphagia in the albino rat. Yale J. Biol. Med. 1943, 15, 831.

15. Hollifield, G., and Parson, W. Studies of the satiety response in mice. J. clin. Invest. 1957, 36, 1638.

16. Finger, F. W. The effect of food deprivation and subsequent satiation upon general activity in the rat. J. comp. physiol. Psychol. 1951, 44, 557.

17. Cohn, C., and Joseph, D. Role of rate of ingestion of diet on regulation of intermediary metabolism ("meal eating" vs "nibbling"). Metabolism 1960, 9, 492. 